\title{
An Overview on VSC-HVDC Power Transmission Systems
}

\author{
Zhenying Pei ${ }^{1}$, Peng Liu ${ }^{1}$, Aijun Zhang ${ }^{2}$, Yaping Zhou ${ }^{1}$ \\ 1 Shenyang Institute of Engineering, Shenyang, Liaoning, P. R. C. \\ 2 School of Continuing Education, Shenyang Institute of Engineering, Shenyang \\ peizy@sie.edu.cn
}

\begin{abstract}
The Voltage Source Converter based High Voltage Direct Current(VSC-HVDC) is a new generation HVDC technology. Because of the technology of the PWM and the turnon and turn-off electronic apparatus, VSC-HVDC could make up for the defective of the traditional HVDC. And the development is rapid. This paper introduces some operation principle and summarizes instances. Firstly, the paper introduces the structure and operation principle of VSC-HVDC. Then the paper states the technology characteristic of VSC-HVDC and the application field. In the end of the paper, the paper discusses the situations of the VSC-HVDC in China and other countries.
\end{abstract}

Keywords: PWM, HVDC, IGBT, voltage source converter, control strategy

\section{Introduction}

With the increasingly energy tense and the serious pollution, the China is vigorously developing and using the renewable energy sources[4]. Because the using of wind energy, solar energy and other renewable energy is increasing, and it makes the conventional AC power transmission not to be very economy that the new energy is dispersion, small scale, far away from the center of power. Advances in technology and the rapid development of electronic control technology can solve the above problems on the HVDC[3]. It is possible that the converter station use the IGBT, IGCT to assemble the voltage source converter to transport current. The foreign companies represented by ABB developed HVDC (HVDC Light) technology and applied in many fields. It is based on the voltage of the device can be turned off source converter and PWM technology for HVDC[5]. From the view of the technical characteristics and the actual engineering point, it is suitable for the renewable energy, power islands, urban power grid and the merging grid of the distributed generation[1].

\section{The Structure and Operation Principle of VSC-HVDC}

The VSC-HVDC is different from the HVDC based on the current source converter. The VSC-HVDC is based on the technology of IGBT and PWM. Firstly the technology can decoupling control the active power and the reactive power by itself. Second it can offer the power to the passive network, the communication is not required between the converter stations. Finally it is easy to structure the multiterminal DC system. Moreover, it can provided the active power and the reactive power for the emergency. It can complete better for enhancing the system stability and the transfer capability.

\section{1. The Structure of VSC-HVDC}

The single-line diagram of a VSC-HVDC system is depicted in the Figure 1. The converter stations at both ends of the structure are VSC. It consists of a current 
converter, converter transformers, converter reactors, DC capacitor and AC Filter[10].

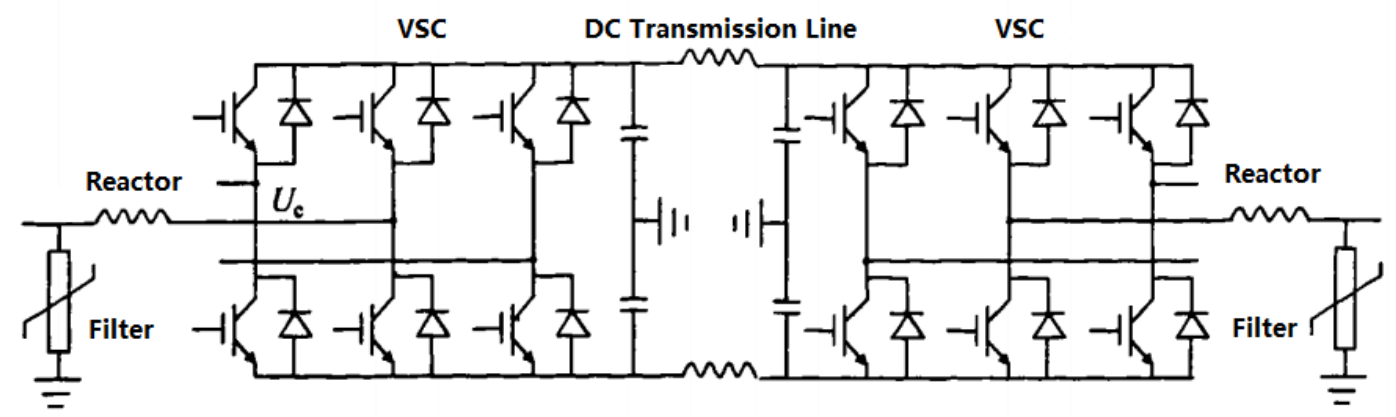

Figure 1. Single-line Diagram of a VSC-HVDC System [21]

(1) Voltage Source Converter

The bridge legs of VSC is consists of high-power shutdown devices (IGBT, IGCT) and the inverse parallel diodes. With the development of the high-power electronic devices, the withstand voltage level of IGBT is $6.5 \mathrm{kV}$ and the current on or off is $3 \mathrm{kA}$; The peak voltage of the off state repeated is $6 \mathrm{kV}$, the maximum current of turning off is $3 \sim 6 \mathrm{kA}$. There are two types topological structures on converter, such as two electrical level and three electrical level[12]. The switch mode are the sine pulse width modulation and the optimal PWM and so on. The switching frequency is declining so the losses are declining.

The two electrical level converter is the most simple topology structure to be used in the VSC-HVDC. It is described in the Figure 2(a). There are six bridge legs in the converter. Every bridge leg consists of a IGBT and a positive electrode method diode. In the Figure 2(b), it is the topology of the neutral-point-clamped three electrical level converter. When the voltage and the power are large, the bridge legs consists of that more IGBT and the reverse parallel diodes to series together. The number of the series device is related to the rated power and the voltage grade of the converters, the capability of switching of the electronic switch devices and the compressive strength.

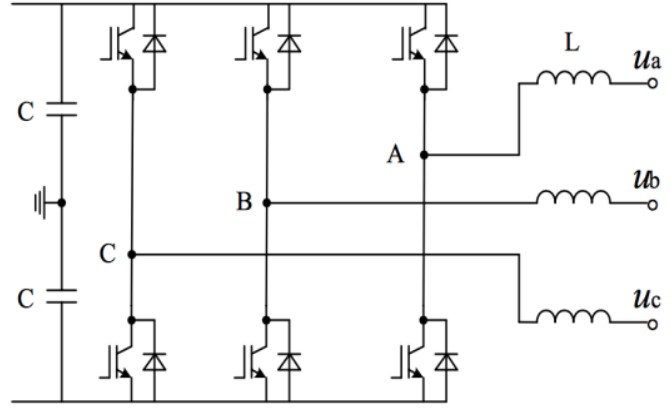

(a)

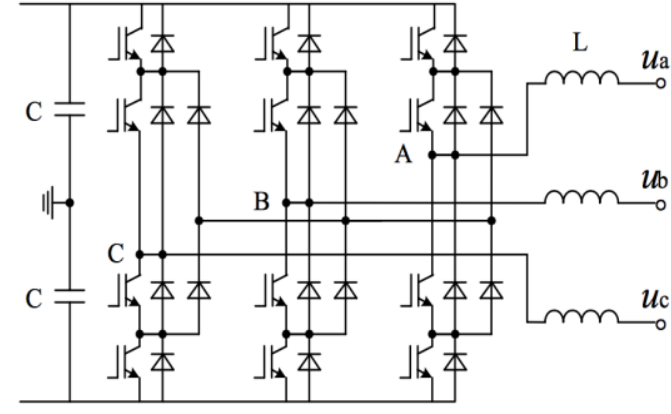

(b)

Figure 2. Typical Topologies for VSC-HVDC[10]

(2) Transformer

The conventional single-phase transformer and three-phase transformer are used in the system. The secondary side winding need a tap switch for getting the maximum active power and reactive power. The reference of secondary side is regulated by regulating tap so that the capability of transferring maximum active power and reactive power is obtained. In addition the star type connection is used in the winding of primary side. The other side is the triangular type connection[7]. 
There is no harmonic current component and direct current component in the transformer winding. This connection mode can prevent that the delivering from homopolar component to AC system by the modulation mode. Moreover the threesinding transformer can be used for providing AC anxiliary power supply to the converter station. In addition to this, converter transformer's another role is transforming system's AC voltage to second side voltage that is phase matching converter's DC side voltage. And the modulation depth of switching is no less, the harmonic displacement of output voltage and current.

(3)Converter Reactor

In the VSC, there is a current commutating reactor in every phase. The current commutating reactor play a important role in the VSC. It is the tie to the VSC with the AC system. And it determined the control performance of actor power and the reactor power. The harmonic component of the switching frequency that is belong to the current and the voltage in the converter. So the fundamental voltage and the fundamental current that is expected. The parameters of the converter reactor must be optimal calculated[46].

(4)DC-Side Capacitor

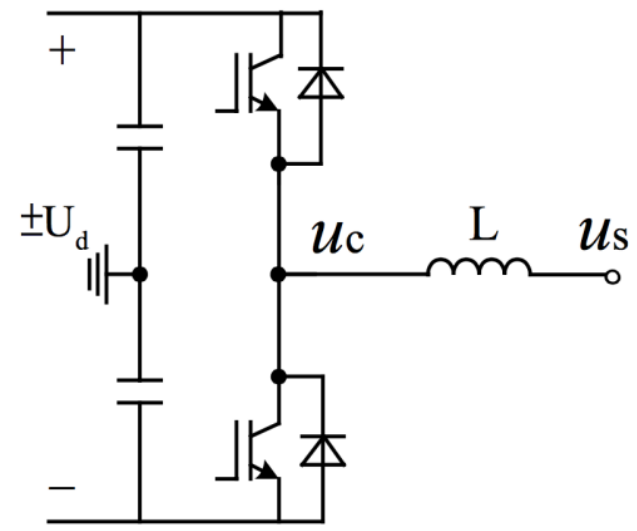

Figure 3. Single-Line Diagram of a VSC [23]

The function of the DC-side capacitor is storing power. And the impulse current of the buffering bridge arm could be slowing down by the capacitor, the DC-side voltage harmonic could be decreased and the voltage support in the receiving end could be provided. In the meantime, the capital of inhibiting the fluctuation of the DC voltage is determined by the DC-capacitor. The performance of the controllers are affected.

(5)AC-Filter

The VSC-HVDC is different from the traditional DC-transmission system that based on the thyristors. The technology of the VSC-HVDC is PWM. When the switching frequency of converter station is slowing down, the low-order harmonics of the AC-current and the AC-voltage is less, and the converter reactor effect the output current, the current measure easy up to standard. When it is no any filtering device, some of higher harmonic will be in the output voltage. The sum of the harmonic aberrance rate is no qualified. Certainly the capacity of converter, the parameter selection are related with the topology structure, switching frequency and other modulation factor. Therefore, the choice of AV filter parameters, depending on the specific circumstances described above. 


\section{2. The Operation Principle of VSC-HVDC}

The VSC-HVDC is different from the traditional DC-transmission technology that based on the thyristor. The VSC-HVDC based on the turn-off device and the technology of PWM. The operation principle is described in the figure 3 and Figure 4. Through comparing the modulation ware and the triangular ware, the upper and lower bridge legs turn on and shut in high frequency. The $u_{c}$ switching fast between the fixed DC-voltage $+U_{d}$ and $-U_{d}$. The $u_{c}$ is filtered by the filter and became the $u_{s}$ in the line side.

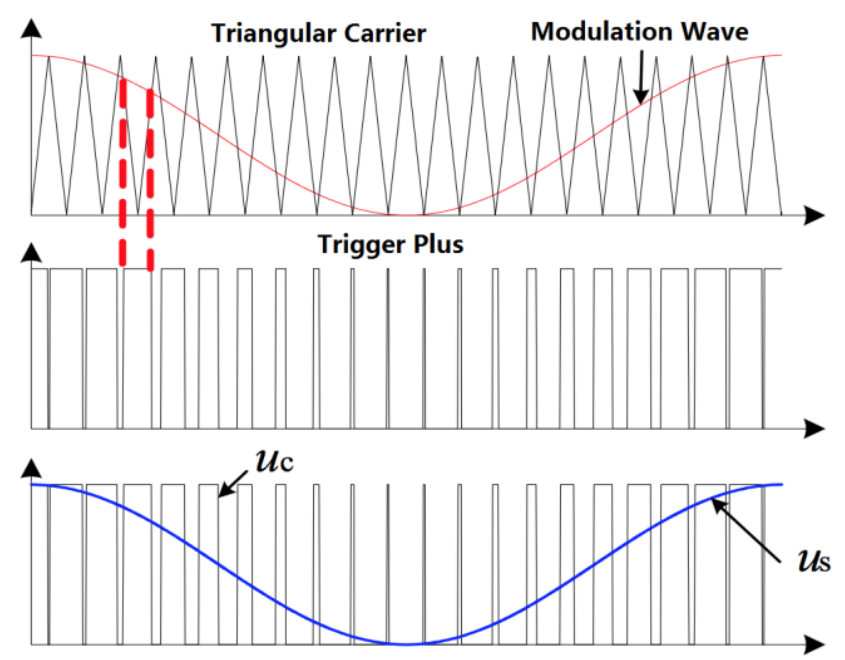

Figure 4. Principle of SPWM[36]

According to further analysis, assuming the converter reactor don't have loss and the harmonic component is ignored. The active power and the reactive power between the converter and the AC-grid are[3]:

$$
\begin{gathered}
P=\left(U_{s} U_{c} / X_{1}\right) \sin \delta \\
Q=U_{s}\left(U_{s}-U_{c} \cos \delta\right) / X_{1}
\end{gathered}
$$

Where $\delta$ is the phase angle between the voltage phasors $U_{s}$ and $U_{c}$ at the fundamental frequency and the $X_{1}$ is the reactive value. From the formula (1) and (2), the steady-state operation fundamental vector diagram of converter is described in the Figure 5. The transmission of the active power determined by $\delta$, and the reactive power determined by $U_{c}$. So, the direction of the DC-current and the value of active power could be controlled by changing the $\delta$. And the reactive power that is sendouted or uptook by controlling the $U_{c}$. From the system, the VSC could be believed a no moment of inertia motor or a generator. The transient regulation of the active power and the reactor power. The fundamental phasor diagram of VSC-HVDC is described in the Figure 5 . 


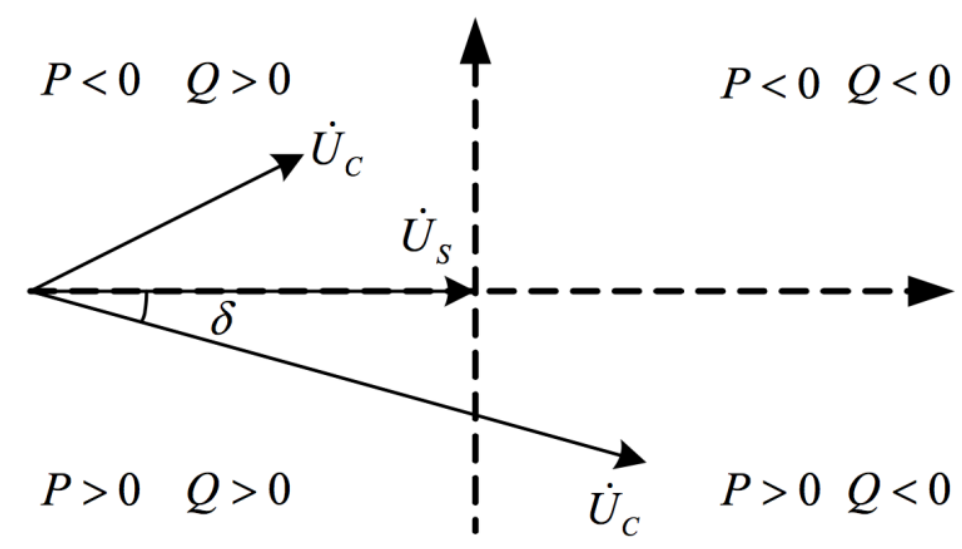

Figure 5. Fundamental Phasor Diagram of VSC-HVDC[4]

\section{The Technology of VSC-HVDC And The Application Field}

The traditional power transmission mode is AC transmission. The technology of the AC power transmission's characteristic include: the operation is convenient, low cost and the variable pressure is simple. The grid structure of the basic network apply the technology of the AC power transmission. But with the increasing of the transmission distance and the transmission capacity, and the mandate of the electric energy quality and the safety of the electric network is more strict. The AC transmission could not meet the demand.

\section{1 The Technology Characteristic of VSC-HVDC}

Comparing the feature of the VSC-HVDC with the AC transmission. The technology characteristic of the VSC-HVDC as follow $[4,6-8,9,10,13]$ :

(1) The current of the VSC could be cut by itself. And the VSC could work on the way of passive power inversion. So the receiving end system can be a passive network. In this way, the power could be transported to the far-flung isolated load.

(2) The active power and the reactive power could be controlled by the VSCHVDC. The controlling will be more flexible and convenient.

(3) When the power flow is opposite, the direction of DC current will change and the direction of DC voltage won't change. This characteristic of the system will convenient control the load flow. And the reliability of the system of the parallel connection multi-terminal DC system will be more reliable.

(4) The technology of PWM is used, the device without the filtering device, and occupy less space.

(5) The design of the modularization make the period of the design, manufacture, installation and debugging is shorter.

(6) The communication between the converter station is not indispensable.

(7) The recovery capability of the system of the VSC-HVDC is excellent. .

\section{2 The Control Strategy of VSC-HVDC}

There are two ways on the control strategy of VSC-HVDC. The first way is about stable operation and another way is about malfunction. And when the system of VSC-HVSC is stable running, the ways of the control is indirect current control and direct current control[7]. The indirect current control is that controlling the amplitude and the phase of the fundamental voltage in the AC-side of the VSC. And the direct current control is the way of current closed-loop. In short, the indirect 
current control's characteristic is that the structure is simple, but the direct control cannot be achieve. The ability of the dynamic response of the direct current control is fast. The component decoupling controlling is easy to be achieved. The performance of robust is well[37].

\section{3 Application Field}

The VSC-HVDC cove come the weak point of the tradition HVDC and possess the advantage of the tradition HVDC. And the application range is vast. The main application range as follow $[9,16,19,22,24,39]$ :

(1) Transporting the power to the city center. With the development of the industry, the electricity-consumption is increasing. The technology of the VSCHVDC is a good method.

(2) Transporting the power to the remote area. The remote area is far away from the grid, its load is light and the fluctuate of load is large. The economic factors and the transporting ability restrict AC transmission. So the VSC-HVDC could enhance the transmission power, decrease the workload and enhance the reliability of the power supply.

(3) Connecting the dispersed small power plants. Such as the hydroelectric plant, wind power plant and the solar power station and so on. The VSC-HVDC provids connectivity to the main network is the best way to make full use of renewable energy and it could protect the environment.

(4) The VSC-HVDC could improve the power quality of the network. The active power and the reactive power could be controlled in independent. The voltage of the AC system can be kept changeless. The voltage and current of the system could satisfy the quality standards.

\section{Development in Foreign Countries}

The DC-transmission was used in the early development of the electric power industry, DC could not to transform, and it is only used in short haul transmission[9]. With the development of the technology, the DC-transmission is believed a effective means to transmit hypertension, large-capacity and longdistance power in 1930s. With the mercury arc valve was invented, the DCtransmission come back in the limelight[10]. CIGRE that is authoritative academic organization in the electric power and IEEE call it "VSC-HVDC". Nowadays, it is called HVDC light and registered trademark. It is called HVDC Plus by SIEMENS[9].

Since 1997 the first VDC-HVDC power transmission project had been established, above 30 VSC-HVDC power transmission projects have been in the commercial operating. Most of these projects are built by ABB and SIEMENS. And the technology is used in the wind power generation, electricity trade, power system interconnection and the supply power to the sea drilling platform[45]. The foreign countries' VSC-HVDC projects and their basic parameters are described in Table 1. And here are some typical project to be briefed. 
Table 1. Foreign Countries' VSC-HVDC Projects And Their Basic Parameters $[3,4,9,17,18]$

\begin{tabular}{|c|c|c|c|c|c|c|c|}
\hline $\begin{array}{c}\text { Serial } \\
\text { Number }\end{array}$ & $\begin{array}{l}\text { Project } \\
\text { Name }\end{array}$ & Country & DC voltage & $\begin{array}{l}\text { Power } \\
\text { rating }\end{array}$ & $\begin{array}{c}\text { Length of } \\
\text { DC } \\
\text { cables }\end{array}$ & $\begin{array}{c}\text { Year of } \\
\text { Commission }\end{array}$ & Remark \\
\hline 1 & Hellsjon & Sweden & $\pm 10 \mathrm{kV}$ & $3 \mathrm{MW}$ & $10 \mathrm{~km}$ & 1997 & Test transmission \\
\hline 2 & Gotland & Sweden & $\pm 80 \mathrm{kV}$ & $50 \mathrm{MW}$ & $70 \mathrm{~km}$ & 1999 & Wind power \\
\hline 3 & Eagle Pass & USA & $\pm 15.9 \mathrm{kV}$ & $36 \mathrm{MW}$ & I & 2000 & I \\
\hline 4 & Tjaereborg & Denmark & $\pm 9 \mathrm{kV}$ & 7. $2 \mathrm{MW}$ & 4. $4 \mathrm{~km}$ & 2000 & Wind power \\
\hline 5 & $\begin{array}{l}\text { Terrenora } \\
\text { Interconnect } \\
\text { ion }\end{array}$ & Australia & $\pm 80 \mathrm{kV}$ & $180 \mathrm{MW}$ & $65 \mathrm{~km}$ & 2000 & Energy trade \\
\hline 6 & $\begin{array}{l}\text { Murray } \\
\text { link }\end{array}$ & Australia & $\pm 150 \mathrm{kV}$ & 200MW & $180 \mathrm{~km}$ & 2002 & $\begin{array}{l}\text { Interconnection of } \\
\text { the weak network }\end{array}$ \\
\hline 7 & $\begin{array}{l}\text { CrossSound } \\
\text { Cable }\end{array}$ & USA & $\pm 150 \mathrm{kV}$ & 330MW & $40 \mathrm{~km}$ & 2002 & Energy trade \\
\hline 8 & $\begin{array}{c}\text { Troll a } \\
\text { offchore }\end{array}$ & Norway & $\pm 60 \mathrm{kV}$ & $41 \mathrm{MW}$ & $67 \mathrm{~km}$ & 2005 & Offshore platform \\
\hline 9 & $\begin{array}{l}\text { Estlink } \\
\text { Estonia }\end{array}$ & Finland & $\pm 150 \mathrm{kV}$ & $350 \mathrm{MW}$ & $210 \mathrm{~km}$ & 2006 & $\begin{array}{l}\text { Nonsynchrony } \\
\text { interconnection }\end{array}$ \\
\hline 10 & $\begin{array}{l}\text { NordE. } \\
\text { on } 1\end{array}$ & Germany & $\pm 150 \mathrm{kV}$ & 400MW & $406 \mathrm{~km}$ & 2009 & Wind power \\
\hline 11 & Caprici link & Namibia & $300 \mathrm{kV}$ & 300MW & $970 \mathrm{~km}$ & 2009 & $\begin{array}{l}\text { Interconnection of } \\
\text { the weak network }\end{array}$ \\
\hline 12 & $\begin{array}{c}\text { Valhall } \\
\text { offshore }\end{array}$ & Norway & $150 \mathrm{kV}$ & $78 \mathrm{MW}$ & $292 \mathrm{~km}$ & 2009 & Offshore platform \\
\hline 13 & TransBay & USA & $\pm 200 \mathrm{kV}$ & 400MW & $88 \mathrm{~km}$ & 2010 & $\begin{array}{l}\text { Urban power } \\
\text { supply }\end{array}$ \\
\hline 14 & $\begin{array}{l}\text { Britain } \\
\text { Ireland }\end{array}$ & Britain & $\pm 200 \mathrm{kV}$ & $500 \mathrm{MW}$ & $256 \mathrm{~km}$ & 2012 & $\begin{array}{l}\text { Interconnection of } \\
\text { the network }\end{array}$ \\
\hline 15 & DolWin1 & Germany & $\pm 320 \mathrm{kV}$ & $800 \mathrm{MW}$ & $165 \mathrm{~km}$ & 2013 & Wind power \\
\hline 16 & BorWin2 & Germany & $\pm 300 \mathrm{kV}$ & $800 \mathrm{MW}$ & $200 \mathrm{~km}$ & 2013 & Wind power \\
\hline 17 & HelWin1 & Germany & $\pm 259 \mathrm{kV}$ & 576MW & $130 \mathrm{~km}$ & 2013 & Wind power \\
\hline 18 & SpainFrance & 1 & $\pm 320 \mathrm{kV}$ & $2000 \mathrm{MW}$ & $60 \mathrm{~km}$ & 2013 & $\begin{array}{l}\text { Interconnection of } \\
\text { the network }\end{array}$ \\
\hline 19 & SynWin1 & Germany & $\pm 320 \mathrm{kV}$ & $864 \mathrm{MW}$ & $200 \mathrm{~km}$ & 2014 & Wind power \\
\hline
\end{tabular}

(1) The project of the Hellsjon is the first test project that is based on the VSCHVDC. It connect the different parts of the $10 \mathrm{kV}$ AC-grid. The line is $10 \mathrm{~km}$ and it was used to transport the $50 \mathrm{kV}$ AC. Since the project started, a lot of complex test have been finished. The transmission is steady and the noises, harmonic distortion, telephone interference and the electeomagnetic field have arrived in the requirements.

(2) In the June of 1999, the project of the Gotland worked. This is the first system of the HVDC-Flexible in trading. It supported the help for the using the natural resources. And the project solve the problem of the energy of wind(no support of the voltage and reactive power). The calbe is underground and it could decrease the 
pollution of the circumstance.

(3) August 2000, the first one project of the VSC-HVDC(Tjaereborg) started to work. It is another successful example of the VSC-HVDC with the wind power.

(4) In September 2000, the first VSC-HVDC project was built by AEP and ABB in the USA Eagle Pass. And it finished the interconnection of back-to-back. The project solved so many problems. It enhance the electricity transmission capability of Eagle Pass. The problem of the voltage support in the Eagle Pass grid. And the problem of switching power capacity between the USA and the Mexico. The max transmission power is $36 \mathrm{MW}$, and it works as the way of STATCOM. In addition to, $36 \mathrm{Mvar}$ reactive power was provided to side by it[21].

(5) The VSC-HVDC project of TransBay link the Pittsburg's converter and the Porterlalo converter in San Francisco. A $88 \mathrm{~km}$ high voltage DC electric cable under the San Francisco Bay. The project started to work in 2010. The purpose of the project could transport the power from East Bay to the San Francisco[18]. It could provided the electric power that is need by the San Francisco. Because the points of the power supply accessing had been built, a main function of the converter is change the power transmission to regulate the peak voltage value and the frequency. Because the system of the VSC-HVDC could provide the voltage supply and reduce loss, the security and the reliability of the system in these areas. Owing to this project had been finished, the power could be transport to the centre of the city, and the security of the power supply was enhanced. The circumstance cannot be polluted, because the electric cable is underground.

There are some of the general introduction of foreign projects. The project of VSC-HVDC are building or working in Europe, Oceania, America, Asia and Africa. The overall trend in these engineering techniques is two-level to three-level and to two-level. Most of the projects use the modular multi-level technology.

\section{Domestic Situations}

In China, it is named HVDC Light. For promoting and becoming the independent intellectual property right, the technology was named "VSC-HVDC" by the China Electric Power Research Institute[9]. The development of VSC-HVDC technology in China is slowly. Until 2005, the research of the VSC-HVDC was establishing the system model two-level converter and analyzing simulation. There are less the engineering technology researching[24]. Because the dominant position of the VSCHVDC, so many researching organizations and universities are researching the VSC- HVDC, and obtaining uncommonly achievement[25,42].

\subsection{Introduction of Domestic Project}

(1) In 2006, STATE GRID started the special research of VSC-HVDC and the commission and operation of the Shanghai Nanhui wind power VSC-HVDC project in July 2011. It is the first independent intellectual property right VSC-HVDC project[30]. The power rating is $20 \mathrm{MW}$, DC voltage is $\pm 30 \mathrm{kV}$. This project is a great original achievement in the field of power electronic. The main function of the Shanghai Nanhui VSC-HVDC project is transporting the power of the Shanghai Nanhui wind power to the city. And the wind power field was the biggest wind field in Shanghai. Nanhui VSCHVDC project have two converters and they are linked by DC cable that is $8 \mathrm{~km}$. The converters are 49-level modularization multi-level topological structure[18, 42].

(2) The VSC-HVDC project in Xiamen's DC voltage is $\pm 320 \mathrm{kV}$, and the power rating is $1000 \mathrm{MW}$. The project constitutes the Xiangan Pnegxi converter and the Huli converter. The length is $10.3 \mathrm{~km}$. It is the highest voltage and the largest power project. $(1000 \mathrm{MW} / \pm 320 \mathrm{kV})$. The sum of the line is $50.2 \mathrm{~km}$.

(3) Zhoushan multi-terminal VSC-HVDC project is the first five-terminal VSC- 
HVDC project. Its DC voltage is $\pm 200 \mathrm{kV}$. The converters are bulit in the Dinghai, Daishan, Hengshan, Yangshan and Sijiao. And the length is $141 \mathrm{~km}$. The line length of $220 \mathrm{kV}$ is $21.8 \mathrm{~km}$ and the $110 \mathrm{kV}$ is $9.99 \mathrm{~km}$. This project could meet the mounting load requirement. And it could enhance the quality of the power of the grid[18, 30].

\subsection{Domestic Requirement of VSC-HVDC}

(1) The exploitation of the renewable energy resources are in the limelight. There are abundant wind power in China. The value that can be developed is 230GW[17]. And they are distributed in Southeast coast and its island, Northwest, North China and Eastnorth. Because the wind power is fluctuant and intermittent, it will be an huge challenge when the plenty of wind power mix in the grid. The technology of VSC-HVDC is indispensable for the grid-connected of the wind power .

(2) With the rapid development of social economy of city. The grid of city has became the center of the load. Because of the demand of the electric power is increasing, the burden of the city grid will be heavier[44]. Due to the city space was occupied by buildings, the demand of the cable underground is increasing. And the capacity of reactive power is not enough in the city[45]. These problems increase the dependence of the VSC-HVDC.

(3) The intelligent grid will become the main stream in the future. There are some new challenges about the transmission, distribution and the using of the power. Plenty of the distributed generations connect into the grid that will change the power flow distribution and the structure of the distribution network. The VSCHVDC could flexible control the power flow distribution, the research of the VSCHVDC is key point of the future gird.

\section{Conclusion}

The ecological environment is becoming worse and worse. The main reason of the pollution is the unreasonable using of coal. The way of energy furnishing must be changed. More and more renewable energy, wind power and the solar energy should be utilized. But these energy are in the northwest, the centre of the electric load is in the eastern coastal. The capacity of power transmission will become very important. And with the development of the power electronics devices and the technology of controlling, the capacity of the power transmission will be more powerful. And the energy structure and improvement of VSC-HVDC should be adjusted. The VS-HVDC will get more using in the interconnection of distributed generation, isolated power supply and city power supply.

\section{Acknowledgement}

This work was supported by the Natural Science Foundation of China (Grant Nos. 61372195, and 61371200, 61304069).

\section{References}

[1] B. Fang, Y. G. Zhou, and H. L. Liu, "Electrical Switch", vol. 50, no. 6, (2012).

[2] B. Le, N. Mei, S. Y. Liu, and D. Chen, China Electric Power, (Technology Edition), vol. 6, (2014)

[3] N. Flourentzou, V. G. Agelidis and G. D. Demetriades, IEEE Traansactions On Power Electronics, vol.24, no. 3, (2009)

[4] Z. Xu, H. R. Cheng, High Voltage Engineering. 33, 1 (2007)

[5] W. Wang, S. An, Journal of Shenyang Institute of Engineering (Natural Science), vol.7, no. 3 (2011).

[6] Hao. L, "Simulation of Flexible HVDC Transmission System", Shandong University. (2010).

[7] H. F. Liang, "The HVDC Flexible Systems' Control Strategy and Achieving of its Experimental", System. North China Electric Power University. (2009) 
[8] K. Huang, "Research on VSC-HVDC Using in Liaoning Power Gird", North China Electric Power University. (2014)

[9] B. Le, N. Mei, S. Y. Liu, and S. J. Zhang, Power System Technology, vol. 32, no. 5, (2014).

[10] Y. H. Gao, Journal of Hebei North University (Natural Science Edition), vol. 26, no. 1, (2010).

[11] C. Deng, X. X. Zhou, and R. M. Li, Proceedings of the Csee, vol. 25, no. 6, (2005).

[12] S. Y. Ying, Y. Qu and H. Wu, Jiangsu Electrical Engineering, vol. 32, no. 4, (2013).

[13] L. Weimers, IEEE Power Engineering Review, vol. 18, no. 8, (1998).

[14] R. Grynbaum, B. Halvarsson and A. Facts, Power Delivery Conference Madrid, Spain, vol. 21,no. 6, (1999).

[15] N. Noroozian, A. Edris, and D. Kidd, IEEE Trans. On Power Delivery, vol. 8, no. 4, (2003).

[16] H. J. Zhou, Modern Enterprise Education, vol. 12, no. 3, (2013).

[17] H. H. Hu, J. R. Li, W. H. Yang, and H. J. Li, Electric Power Construction, vol. 32, no. 5 , (2011).

[18] W. M. Ma, F. J. Wu, Y. M. Yang and T. Zhang, High Voltage Engineering, vol. 40, no. 8, (2014).

[19] W. Cui, Energy And Environment, vol. 22, no. 8, (2013).

[20] H. Hu, East China Electric Power, vol. 39, no. 9, (2011).

[21] G. Y. Li, P. F. Lv, G. K. Li and M. Zhou, Power System Automation, vol. 27, no. 4, (2003).

[22] D. L. Hu, C. Y. Zhao and G. K. Li, Southern Power System Technology, vol.2, no. 5, (2008).

[23] C. S. Wang, P. Li, J. Automation of Electric Power Systems, vol. 34, no. 10, (2010).

[24] Z. Q. Hu, C. X. Mao, J. M. Lu and G. D. Li, Transactions of China Electrotechnical Society, vol. 20, no. 7, (2005).

[25] G. F. Tang, Z. Y. He and H. Pang, Automation of Electric Power Systems, vol. 37, no. 15, (2013).

[26] F. You, X. F. Yuan and Y. Liu, Modern Machinery, vol. no.3, (2014).

[27] X. Liu, Z. Y. He, W. G. He and H. L, Bao Power and Energy, vol. 1, no. 1, (2011).

[28] G. H. Liu, C. L. Xu and X. G. Zhang, Journal of Shandong Electric Power College, vol. 14, no. 5, (2011).

[29] J. X. Wang, H. L. Bao and J. Ye, Distribution and Utilization, vol. 28, no. 2, (2011).

[30] S. K. Feng, Henan Science and Technology, vol. 15, no. 3, (2011).

[31] X. Zha, B. D. Z. Pu, China Science and Technology Panorama Magazine, vol. 2, (2014).

[32] X. Liu, W. G. He and H. L. Bao, Distribution and Utilization, vol. 25, no.1, (2008).

[33] M. Wang, L. D. Wang, Agricultural Science and Technology and Equipment, vol. 4, no. 12 , (2011).

[34] J. Liu, Shanghai Electric Power, vol. 1, no. 2, (2009).

[35] G. F. Yuan, Super Science, vol. 3, (2014).

[36] H. R. Wang, "Research on the Control and Protective Strategies for VSC-HVDC", China Three Corges University, (2012).

[37] X. X. Su, Z. J. Wang and L. J. Chen, Shaanxi Electric Power, vol. 24, no. 5, (2014).

[38] J. S. Zhu, Jiangsu Electrical Apparatus, vol. 1, (2014).

[39] B. Shen, Electric Power Construction, vol. 21, no. 6, (2013).

[40] G. W. Chen, Shangqing, vol. 49, (2013).

[41] L. P. Zhao, Morden Enterprise Culture, vol. 21, (2009).

[42] J. S. Zhu, Electrotechnics Electric (Jiangsu Electrical Apparatus), vol. 1, (2014).

[43] C. H. Jiang, Z. X. Wang and D. G. Wang, "Power System and Clean Energy", vol. 28, no. 12, (2012).

[44] Y. Qiu, Guangdong Science \& Technology, vol. 21, no. 15, (2012).

[45] B. Chen, ShuZiHua YongHu, vol. 30, no. 17, (2014).

[46] F. You, X. F. Yuan and Y. Liu, Modern Machinery, vol. 12, no. 3, (2014).

[47] B. Chen, Shuzihua YongHu, vol. 17, (2014).

[48] C. H. Jiang, Z. X. Wu and D. G. Wu, "Advances of Power System \& Hydroelectric Engineering", vol. 28 , no. 12, (2012).

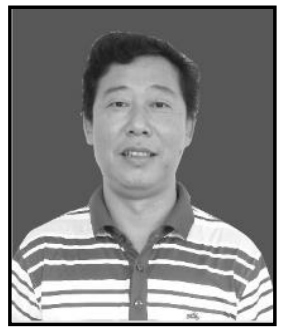

Zhenying Pei. He is a senior engineer in thermal and power engineering profession, received the B.S. degrees in thermal and power engineering from Northeast Electric Power University, Jilin, China. Since then, he has worked in the simulation center of Shenyang institute of engineering, majoring in thermal power station simulation training, power station simulation model study and the vibration analysis and fault diagnosis of large rotation machines. Since 2011, he has taken the office of the director of simulation center, doing a lot attribution to the construction of simulation center. He is one of the experts of China Electricity Council. 


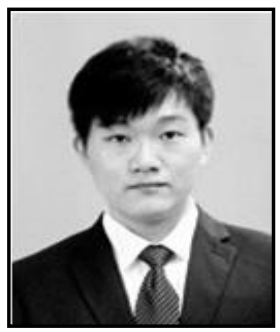

Peng Liu. He received the B. E. degree in Automation from Shenyang Institute of Engineering, Liaoning, China in 2013. He is currently working towards the Master in Electrical Engineering in Shenyang Institute of Engineering.

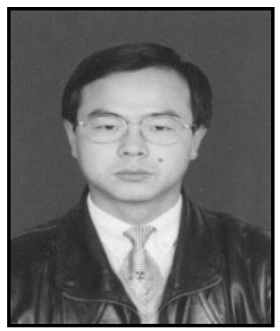

Aijun Zhang. He was born in 1970. He received Master degree, and is an associate professor. He works in continuing education college, Shenyang Institute of Engineering. Recently, his research area contains electrical machine, control system and renewable energy technology.

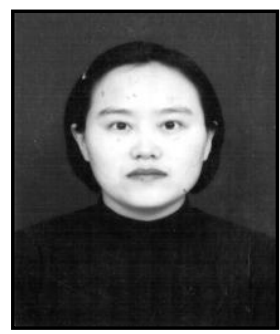

Yaping Zhou, was born in November 1970. She was graduated from Beijing Technology and Business University major in accounting. In 2005, she was awarded senior accountant, and the research direction is financial accounting. 
International Journal of Control and Automation

Vol. 9 No. 5 (2016) 